\title{
Determination of Clinical Decision Rule for Estimation of Bone Mineral Density in Women
}

\author{
Shahram Yazdani ${ }^{a}$ Atousa Iranpour Asli ${ }^{b}$ Afshin Salemi ${ }^{c}$ Arash Iranpour Asli ${ }^{b}$ \\ Mohamad Ali Heidarnia $^{d}$ Parvin Sarbakhsh ${ }^{\text {b }}$ \\ ${ }^{a}$ Education Development Center, ${ }^{b}$ Clinical Excellence Center, ${ }^{c}$ Department of Radiology and d Community \\ Medicine, Shaheed Beheshti University of Medical Sciences, Tehran, Iran
}

\section{Key Words}

Osteoporosis - Women - Risk factor • Bone densitometry •

Clinical decision rule

\begin{abstract}
Objective: This study assessed the relative risk factors for osteoporosis in women referring to the Bone Densitometry Center during 2007, with the aim of designing a formula to estimate the severity of osteoporosis. Subjects and Methods: Data of outpatients ( $n=1,047$ ) who visited the Bone Densitometry Center of Chamran Hospital were gathered by administering a questionnaire to subjects before a dual-energy X-ray absorptiometry (DXA) densitometry test of the hip and vertebrae. Results: Of the 1,047 subjects, 764 (73\%) were menopausal. The average ( \pm SD) age and weight were $54.5 \pm 10.3$ and $69.5 \pm 10.8$, respectively. The average ( \pm SD) $\mathrm{T}$ score of hip and lumbar spine were $-1.88 \pm 1.08$ and $-1.04 \pm 1.05$, respectively. After assessment, the precipitating factors of osteoporosis of the hip were age, menopause, duration of menopause, history of fracture, history and dosage of calcium supplementation, parity and duration of breastfeeding. Protective factors were weight, history
\end{abstract}

of oral contraceptive pill consumption, and exercise, being significant $(p<0.05)$. Precipitating factors in osteoporosis of vertebrae were age, menopause and duration of menopause, diabetes, history of fracture, history and dosage of calcium supplementation, parity and duration of breastfeeding, with weight as a protective factor $(p=<0.05)$. Using stepwise regression analysis, a minimal mathematical model for prediction of bone density of the hip and lumbar spine was formulated. Conclusion: Using the mathematical model, along with clinical findings and history, persons at risk of osteoporosis may be identified and early prevention and treatment made possible. Unnecessary expenses of diagnostic procedures for people without the risks of osteoporosis can also be prevented.

Copyright $\odot 2011$ S. Karger AG, Basel

\section{Introduction}

Osteoporosis is the most common bone disease in which bones become fragile and fracture easily in the absence of or with minimal trauma. Fractures lead to increased mortality and morbidity, impair quality of life

\section{KARGER}

Fax +4161306 1234

E-Mail karger@karger.ch

www.karger.com
(C) 2011 S. Karger AG, Basel

1011-7571/11/0205-0416\$38.00/0

Accessible online at:

www.karger.com/mpp
Dr. Atousa Iranpour Asli

Department of Clinical Excellence, Taleghani Hospital

Shaheed Beheshti University of Medical Sciences

Evin, Yaman Street, Tehran (Iran)

Tel. +98 2122432485 6, E-Mail ats.iranpour@yahoo.com 
and impose significant health costs. Osteoporosis and related fractures are gaining increasing attention in health management systems around the world. According to the World Health Organization (WHO), 1.7 million hip fractures occurred worldwide. Considering the change in the demographic pattern of populations the number will reach 6 million by 2050 [1]. Therefore, osteoporosis and its consequent increase in fracture risk is a major health concern for postmenopausal women and older men with the potential to reach epidemic proportions [2].

It is estimated that hip fractures alone will cause 700,000 annual deaths and 2.6 million cases of disability in 2025 [3, 4]. Treatment and rehabilitation of osteoporosis-related fractures result in huge financial losses. Direct costs of hip, vertebral, and nonhip nonvertebral fractures are very high [5]. According to several studies in Western countries, the cost of treatment for a hip fracture is estimated to be $\$ 20,000$ at the end of the first year [6]. WHO reported that osteoporotic fractures cause 2.8 million disability-adjusted life years annually. In 2002, osteoporosis caused 36,026 lost years in Iran alone [7]. Because of the magnitude of the problem, screening and treatment of people at risk are recommended [8]. Limitations of bone densitometry and the high cost of this procedure have led many authorities to consider an individual's risk factors and age before recommending its use $[9,10]$. In order to optimally use dual-energy X-ray absorptiometry (DXA) equipment, physicians need tools to identify individuals at risk of osteoporosis and refer them for bone mass densitometry. Such tools have been developed in the form of indices and formulas based on known risk factors [11-15]. Most of these formulas have been developed in the Western world and are adapted for Western populations. Since risk factors and their influences differ among various populations, we attempted to develop a mathematical model based on risk factors relevant for Iranian women, in predicting bone mass density using a number of given variables. Furthermore, we tried to define a cutoff value in this model to identify high-risk individuals and limit the use of DXA to this subgroup of patients, thereby ideally reducing unnecessary cost.

\section{Subjects and Methods}

Data were collected for 1,047 outpatient women who were referred for bone mineral densitometry (BMD) to Chamran Hospital between April and November 2007 from hospitals and private practice clinics. All women were included in a cross-sectional analytical study. Upon presentation, a trained physician weighed all participants with a minimum of clothing and without shoes using a Seca scale with an accuracy of $\pm 100 \mathrm{~g}$ (after every 10 measurements the scale was adjusted using a standard weight). Then, participants' barefoot standing height was measured with a ruler placed on the head with an accuracy of $1 \mathrm{~mm}$. Separate questionnaires including demographic items and risk factors were completed in a face-to-face interview with each participant. Recorded variables included age, weight, height, menopause status (cessation of menstrual flow at least 1 year prior to the densitometry test), age of menopause, history and duration of diabetes (years), history and duration of hypothyroidism (years), history of rheumatoid arthritis, history of hip, forearm, or vertebral fracture after 40 years of age, family history of fractures, smoking, oral contraceptive pill (OCP) usage, hormone replacement therapy (HRT) and duration, breastfeeding and duration, parity, lactose intolerance, duration and dosage of calcium-vitamin D consumption, history of corticosteroid therapy $7.5 \mathrm{mg}$ daily prednisone equivalent for at least 3 months, history of cytotoxic drug use, history and duration of levothyroxin treatment, and physical activity equal to $30 \mathrm{~min}$ per day and at least 3 times weekly. Research ethics were strictly observed by obtaining informed consent and absolutely confidential handling of personal data.

A DXA bone mass density test was subsequently performed for femoral neck, L2-L4 vertebrae using a Norland densitometer. Results were interpreted by a radiologist and the severity of osteoporosis was defined using WHO guidelines ( $\mathrm{T}$ score $\geq-1$ normal bone mineral density, T score between -1.0 and -2.5 osteopenia; T score -2.5 or below osteoporosis). A data bank was designed and data were analyzed using SPSS version 15 . All variables were checked for missing data $(1,047$ cases that have no missing data on all variables were included in the regression model). Quantitative variables were expressed as mean \pm SD or median and qualitative variables were expressed as percentage points. The Kolmogorov-Smirnov test was used to test the normality of quantitative variable distribution. The correlation between normal quantitative variables and T score was tested by Pearson correlation coefficient and the Spearman coefficient was used for quantitative variables that lacked normal distribution. Quantitative variables were compared among normal, osteopenic and osteoporotic individuals by one-way analysis of variance and KruskalWallis test; $\chi^{2}$ test was used for comparison of qualitative variables. In regression analysis, the presence of colinearity was ruled out by measuring the variance inflation factor. To develop a regression model between the $T$ score and available variables, first the relation between the $T$ score and each variable was tested separately as a single variable analysis. Subsequently, variables that were significant at 0.2 level were inserted into the multiple regression model and their simultaneous effect on the T score was assessed by stepwise multiple regression. Eventually, predictive models were reported for hip and vertebral bone mass using stepwise multiple regressions. Afterwards, a simplified model for clinical decision making was developed by attributing coefficients to the regression model developed for hip and the mathematical model was redefined as a clinical decision rule. To assess the efficiency of the model, it was applied to 100 other women who were similar to the participants of the study. These women were divided into two groups based on T scores predicted by the model for each using -2.5 as a cutoff score. Actual data were also divided into two groups using the same -2.5 score. Sensitivity and specificity of the model were then measured using this cutoff score. 
Table 1. Basic characteristics of participants according to hip BMD

\begin{tabular}{lcccc}
\hline & Normal & Osteopenia & Osteoporosis & p value \\
\hline Participants, $\mathrm{n}$ & 194 & 557 & 295 & \\
Age, years & $49.1 \pm 10.2$ & $52.7 \pm 9.2$ & $61.7 \pm 10.2$ & $<0.001$ \\
Weight, kg & $74.0 \pm 12.6$ & $70 \pm 10.5$ & $65.8 \pm 9.7$ & $<0.001$ \\
Height, cm & $161.2 \pm 5.9$ & $159.5 \pm 5.4$ & $157.8 \pm 5.4$ & $<0.001$ \\
Duration of breastfeeding, years & $3.6 \pm 3.1$ & $4.4 \pm 3.7$ & $5.9 \pm 5.1$ & $<0.001$ \\
Parity, median (range) & $3(8)$ & $3(12)$ & $4(12)$ & $<0.001$ \\
Menopause, \% & 52.6 & 70.1 & 91.9 & $<0.001$ \\
Diabetes mellitus, \% & 11.8 & 6.6 & 6.7 & 0.05 \\
Physical activity, \% & 29.4 & 22.1 & 17.9 & 0.01 \\
History of fracture, \% & 2.1 & 5.1 & 11.2 & $<0.001$ \\
History of OCP usage, \% & 7.7 & 6.5 & 3.4 & 0.08 \\
Calcium supplementation & 37.6 & 49.8 & 49.1 & 0.01 \\
\hline
\end{tabular}

Data for age, weight, height and breastfeeding shown as mean \pm SD.

Table 2. Basic characteristics of participants according to vertebral BMD

\begin{tabular}{lcccc}
\hline & Normal & Osteopenia & Osteoporosis & p value \\
\hline Participants, n & 492 & 460 & 91 & \\
Age, years & $50.5 \pm 9.4$ & $57.3 \pm 9.8$ & $62 \pm 8.7$ & $<0.001$ \\
Weight, kg & $71.8 \pm 11.1$ & $68.4 \pm 10.5$ & $63.5 \pm 10.2$ & $<0.001$ \\
Height, cm & $160.2 \pm 5.7$ & $159.0 \pm 5.4$ & $155.9 \pm 4.8$ & $<0.001$ \\
Duration of breastfeeding, years & $3.9 \pm 3.2$ & $5.3 \pm 4.5$ & $6.3 \pm 5.5$ & $<0.001$ \\
Parity, median (range) & $3(9)$ & $3(12)$ & $4(10)$ & $<0.001$ \\
Menopause, \% & 57.5 & 85.4 & 94.5 & $<0.001$ \\
Diabetes mellitus, \% & 8.3 & 7.4 & 5.5 & 0.6 \\
Physical activity, \% & 25 & 19.1 & 24.2 & 0.08 \\
History of fracture, \% & 3.7 & 8.1 & 9.9 & 0.006 \\
History of OCP usage, \% & 6.9 & 4.8 & 5.5 & 0.37 \\
Calcium supplementation & 42.5 & 52.5 & 48.3 & 0.008 \\
\hline
\end{tabular}

Data for age, weight, height and breastfeeding shown as mean \pm SD.

\section{Results}

Five hundred and fifty-eight $(558,53.2 \%)$ of the women were osteopenic of the hip and 295 (28.2\%) were osteoporotic. Table 1 shows the characteristics of participants according to hip bone mineral density. In lumbar vertebrae, $460(43.9 \%)$ and $91(8.7 \%)$ women were diagnosed to be osteopenic and osteoporotic, respectively. Seven hundred and sixty-four $(764,73 \%)$ women had reached menopause. Mean \pm SD for age and weight of the women under study were $54.5 \pm 10.3$ years and $69.6 \pm 10.8 \mathrm{~kg}$, respectively. Table 2 shows the characteristics of participants according to vertebral bone mineral density. Women had 3.5 partu- ritions on average (median $=3$ ). Hip and vertebral T scores were $-1.88 \pm 1.08$ and $-1.04 \pm 1.05$, respectively.

Single variable regression analysis showed that factors predicting vertebral osteoporosis were age, duration of menopause, history of fracture, history and amount of calcium supplementation, parity and duration of breastfeeding ( $\mathrm{p}<0.001$, table 3 ). Weight was a protective factor $(\mathrm{p}<0.01)$. Stepwise multiple regression analysis showed that age, weight, menopause status and parity have the greatest impact on predicting vertebral bone mass density $\left(\mathrm{p}<0.05, \mathrm{R}^{2}=0.270\right)$.

$\mathrm{T}$ spin $=-1.93-0.016$ age +0.026 weight -0.560 menopause -0.052 delivery 
Table 3. Multiple stepwise regression analysis of vertebral bone T score

\begin{tabular}{lllr}
\hline Variable & $\begin{array}{l}\text { Regression } \\
\text { coefficient }\end{array}$ & $\begin{array}{l}\text { Standard } \\
\text { error }\end{array}$ & p value \\
\hline Constant coefficient & -1.93 & 0.391 & $<0.001$ \\
Age, years & -0.016 & 0.005 & 0.001 \\
Weight, kg & 0.026 & 0.003 & $<0.001$ \\
Menopause & -0.560 & 0.104 & $<0.001$ \\
Parity & -0.052 & 0.021 & 0.019 \\
\hline
\end{tabular}

Table 4. Multiple stepwise regression analysis of hip T score

\begin{tabular}{lclr}
\hline Variable & $\begin{array}{l}\text { Regression } \\
\text { coefficient }\end{array}$ & $\begin{array}{l}\text { Standard } \\
\text { error }\end{array}$ & p value \\
\hline Constant coefficient & -0.94 & 0.29 & 0.002 \\
Age, years & -0.04 & 0.003 & $<0.001$ \\
Weight, kg & 0.024 & 0.003 & $<0.001$ \\
Menopause & -0.23 & 0.078 & 0.003 \\
Physical activity & 0.35 & 0.068 & $<0.001$ \\
History of fracture & -0.37 & 0.117 & 0.002 \\
OCPs & 0.25 & 0.119 & 0.036 \\
\hline
\end{tabular}

Similarly, for the hip, single variable regression analysis showed that pro-osteoporotic factors were age, duration of menopause, history of fracture, history and amount of calcium supplementation, parity and duration of breastfeeding $(\mathrm{p}<0.001$, table 4$)$. Weight, OCP usage and physical activity were shown to be protective $(p<0.01)$. Stepwise multiple regression analysis showed that age, weight, menopause status, history of fracture, OCP usage and physical activity have the greatest impact on predicting hip bone mass density $\left(\mathrm{p}<0.05, \mathrm{R}^{2}=\right.$ $0.304)$.

$\mathrm{T}$ hip $=-0.941-0.04$ age +0.024 weight -0.236 menopause -0.366 history of fracture +0.354 exercise +0.251 OCP

In order to identify individuals at increased risk of osteoporosis who require treatment and to determine the need for referral for BMD, a function was defined and simplified using the aggravating factors for hip osteoporosis mentioned above. Validity of this model was tested by applying it to 100 women who were cohort controls of the participants. The stated function is:

- Age $^{* *}+$ weight $^{* *}-$ menopause -1.5 (history of fracture) + $\mathrm{OCP}+1.5$ exercise

Estimation of Bone Mineral Density where Age $\mathrm{A}^{* *}=$ age $-50 / 5$ and weight ${ }^{* *}=$ weight $-50 / 10$. One point was subtracted for every 5 years over the age of 50 years or if the subject had reached menopause. One point was added for every $10 \mathrm{~kg}$ above $50 \mathrm{~kg}$ and if the subject had a history of OCP usage. If the subject had a history of osteoporotic fracture (wrist, hip, vertebrae in subjects older than 40 years), 1.5 points were subtracted. For sufficient physical activity (more than $30 \mathrm{~min}$ at least 3 times a week), 1.5 points were added.

A total score less than -1 indicates osteoporosis. A score between -1 and 5 indicates osteopenia. A total score above 5 is considered normal. For the hip, ROC for our suggested model was 0.749 (95\% CI: 0.713-0.786); ROC for the Osteoporosis Risk Assessment Instrument (ORAI) score was 0.687 (95\% CI: 0.642-0.733) and for the Osteoporosis Self-Assessment Tool (OST) was 0.724 (95\% CI: $0.685-0.764)$. Sensitivity and specificity for ORAI was 48.9 and $78 \%$, respectively, and was 40.6 and $84 \%$, respectively for OST. For other predictive scores such as SCORE and OSIRIS, we did not have some of the needed variables and therefore, we were not able to compute the predictive value of them for comparison with our model.

Sensitivity of our mathematical model for high-risk individuals is $80 \%$ with a $95 \%$ confidence interval ( $95 \%$ $\mathrm{CI}=72-87 \%)$. Specificity is $70 \%(95 \% \mathrm{CI}=61-78 \%)$.

\section{Discussion}

The results of our study of 1,047 women referred for BMD showed a significant relationship between a number of known risk factors and the severity of osteoporosis. As shown by previous studies, bone density decreases with age [16]. Burger et al. [17] reported that a fraction of bone mass decreases each year after menopause due to decreased estrogen level. Menopausal women in our study had lower bone density. There was no relation observed in our study between family history of osteoporosis and bone mass density. It is probable that the presence of more significant risk factors such as menopause, age, weight, parity, and history of fracture has weakened the effect of family history. Future studies may prove a decreased influence of family history on osteoporosis in Iranian women. A study conducted in 2004 in Tehran, Iran, supports this theory since it also failed to document a relation between family history and osteoporosis [18], whereas it did identify the influence of fracture over 40 on subsequent femoral and vertebral bone mass, as reported in other studies [19]. A negative correlation between weight and development of osteoporosis observed 
in similar studies was confirmed in our own [20]. Smoking has been suggested to be pro-osteoporotic since nicotine causes a general acidic state in the body and facilitates bone resorption [21]. However, we failed to demonstrate such a correlation probably due to the low prevalence of smoking in Iranian women. Interestingly, in our study, consumption of calcium and vitamin D supplements had a negative effect on bone mass density. Possible explanations include the effect of a compounding factor that was more prevalent among women who took regular calcium-vitamin D supplements or a false assurance about osteoporosis prophylaxis that led to decreased attachment to healthy preventive behavior. Our results show a positive relation between osteoporosis and parity. A similar study in 2004 also reported a positive relation between duration of breastfeeding and osteoporosis [18, $22,23]$. We noted a negative correlation between physical activity and hip osteoporosis but failed to establish any correlation for vertebral osteoporosis. A review of the literature showed conflicting results $[17,18]$. Additionally, we could not demonstrate a relationship between osteoporosis and corticosteroid usage, anticonvulsant medications, hyperthyroidism or diabetes mellitus, possibly due to scarcity of samples. Use of OCPs was shown to have a positive effect on hip density, whereas postmenopausal HRT was not significantly related to bone mass density. The paucity of women on HRT may explain this observation; however, controversy exists in this regard [24].

There have been a number of attempts to develop a mathematical model to estimate the severity of osteoporosis in the past [11-15]. In the present study, after testing various combinations of variables that may have an effect on osteoporosis, a function was defined based on six principal factors that influenced hip osteoporosis, namely, age, weight, menopause, history of fracture, physical activity, and history of OCP usage. The function was further simplified and converted to a practical formula that can aid physicians in making a decision about whether a patient is at increased risk and needs a BMD. In the next step, the formula was tested on a cohort of 100 women and proved to have good sensitivity (80\%) and acceptable specificity (70\%). In this way the formula can identify people who need a BMD and prevent financial loss due to unnecessary testing. The decision rules developed for osteoporosis have moderate to high sensitivity and low specificity. The ORAI uses age, weight, and HRT for identification of women at increased risk of osteoporosis and has a sensitivity of $94 \%$ and specificity of $41 \%$, which is significantly low compared to our proposed rule [14]. The model developed by Women's Health Initiative in 2007 uses age, subject's self-report of health, weight, height, race, reported physical activity, history of fracture, history of hip fracture in parents, smoking, corticosteroid usage and diabetes to predict the risk of hip fracture. This model has preferable sensitivity (79\%) and specificity (71\%) but requires significantly more items to be calculated compared to our model [15]. The OST uses age and weight. This model has sensitivity (97\%) and specificity (40\%) [25].

However, data were collected from women who presented to outpatient clinics and the resultant findings may assist physicians regarding the decision to refer a patient for BMD. There may have been additional factors influencing bone mineral density that were not included in our study and should be addressed in future research.

\section{Conclusion}

Screening according to the model presented has two advantages: first, early screening for at-risk individuals can serve as the mainstay of prevention and treatment of osteoporosis by preventing fractures and related treatment costs; second, it reduces unnecessary testing of individuals with low risk, thereby reducing the cost of testing.

The formula developed can be validated in the general population by future research and converted to a useful tool for identification of people at risk of osteoporosis, while in the meantime, it can prevent unnecessary and expensive testing.

References

1 World Health Organization: Prevention and management of osteoporosis. World Health Organ Tech Rep Ser 2003;921:1-164.

2 Salaffi F, Silveri F, Stancati A, Grassi W: Development and validation of the osteoporosis prescreening risk assessment (OPERA) tool to facilitate identification of women likely to have low bone density. Clin Rheumatol 2005; 24:203-211.

-3 Gullberg B, Johnell O, Kanis JA: World-wide projections for hip fracture. Osteoporos Int 1997;7:407-413.

-4 Kanis JA, Oden A, Johnell O, Jonsson B, de Laet C, Dawson A: The burden of osteoporotic fractures: a method for setting intervention thresholds. Osteoporos Int 2001;12: 417-427.

5 Christensen L, Iqbal S, Macarios D, Badamgarav E, Harley C: Cost of fractures commonly associated with osteoporosis in a managed-care population. J Med Econ 2010; 13:302-313.
Yazdani/Iranpour Asli/Salemi/ Iranpour Asli/Heidarnia/Sarbakhsh 
6 Johnell O: The socioeconomic burden of fractures: today and in the 21st century. Am J Med 1997;103:20S-25S.

7 Abolhasani F, Soltani A, Mohamadi M: The burden of osteoporosis in Iran (in Farsi). J Fertil Infertil 2004;6:25-36.

$>8$ US Preventive Services Task Force: Screening for osteoporosis in postmenopausal women: recommendations and rationale. Ann Intern Med 2002;137:526-528.

$>9$ Kanis JA, Delmas P, Burckhardt P, Cooper C, Torgerson D: Guidelines for diagnosis and management of osteoporosis. The European Foundation for Osteoporosis and Bone Disease. Osteoporos Int 1997;7:390-406.

10 Raisz LG: Clinical practice: screening for osteoporosis. N Engl J Med 2005;353:164-171.

$\checkmark 11$ Koh LK, Sedrine WB, Torralba TP, Kung A, Fujiwara S, Chan SP, Huang QR, Rajatanavin R, Tsai KS, Park HM, Reginster JY: Osteoporosis Self-Assessment Tool for Asians (OSTA) Research Group: A simple tool to identify Asian women at increased risk of osteoporosis. Osteoporos Int 2001;12:699-705.

12 Van der Voort DJ, Dinant GJ, Rinkens PE, van der Voort-Duindam CJ, van Wersch JW, Geusens PP: Construction of an algorithm for quick detection of patients with low bone mineral density and its applicability in daily general practice. J Clin Epidemiol 2000;53: 1095-1103.
13 Cadarette SM, Jaglal SB, Kreiger N, McIsaac WJ, Darlington GA, Tu JV: Development and validation of the Osteoporosis Risk Assessment Instrument to facilitate selection of women for bone densitometry. CMAJ 2000; 162:1289-1294

14 Cadarette SM, Jaglal SB, Murray TM, McIsaac WJ, Joseph L, Brown JP, Canadian Multicentre Osteoporosis Study: Evaluation of decision rules for referring women for bone densitometry by dual-energy $\mathrm{x}$-ray absorptiometry. JAMA 2001;286:57-63.

15 Robbins J, Aragaki AK, Kooperberg C, Watts N, Wactawski-Wende J, Jackson RD, LeBoff MS, Lewis CE, Chen Z, Stefanick ML, Cauley J: Factors associated with 5-year risk of hip fracture in postmenopausal women. JAMA 2007;298:2389-2398.

16 Melton LJ 3rd: Epidemiology worldwide. Endocrinol Metab Clin North Am 2003;32:113.

17 Burger H, de Laet CE, van Daele PL, Weel AE, Witteman JC, Hofman A, Pols HA: Risk factors for increased bone loss in an elderly population: the Rotterdam Study. Am J Epidemiol 1998;147:871-879.

18 Jamshidian Tehrani M, Kalantari N, Azadbakht L, Rajaie A, Hooshiar-rad A, Golestan B, Kamali Z: The prevalence of osteoporosis among women aged 40-60 in Tehran. Iran J Endocrinol Metab 2003;5:271-276 (Farsi).
19 Kanis JA, Johnell O, Oden A, Johansson H, McCloskey E: FRAX and the assessment of fracture probability in men and women from the UK. Osteoporos Int 2008;19:385-397.

20 Green AD, Colón-Emeric CS, Bastian L, Drake MT, Lyles KW: Does this woman have osteoporosis? JAMA 2004;292:2890-2900.

21 Melton LJ 3rd, Atkinson EJ, O’Connor MK, O'Fallon WM, Riggs BL: Bone density and fracture risk in men. J Bone Miner Res 1998; 13:1915-1923.

-22 Karlsson MK, Ahlborg HG, Karlsson C: Maternity and bone mineral density. Acta Orthop 2005;76:2-13.

23 Holmberg-Marttila D, Leino A, Sievänen H: Bone turnover markers during lactation, postpartum amenorrhea and resumption of menses. Osteoporos Int 2003;14:103-109.

24 Cauley JA, Robbins J, Chen Z, Cummings SR, Jackson RD, LaCroix AZ, LeBoff M, Lewis CE, McGowan J, Neuner J, Pettinger M, Stefanick ML, Wactawski-Wende J, Watts NB, Women's Health Initiative Investigators: Effects of estrogen plus progestin on risk of fracture and bone mineral density: the Women's Health Initiative randomized trial. JAMA 2003;290:1729-1738.

25 Richy F, Gourlay M, Ross PD, Sen SS, Radican L, De Ceulaer F, Ben Sedrine W, Ethgen $\mathrm{O}$, Bruyere O, Reginster JY: Validation and comparative evaluation of the Osteoporosis Self-Assessment Tool (OST) in a Caucasian population from Belgium. QJM 2004;97:3946. 